\title{
An inventory of European data sources for the long-term safety evaluation of methylphenidate
}

\author{
Macey L. Murray • Suppachai Insuk • Tobias Banaschewski • Antje C. Neubert • \\ Suzanne McCarthy $\cdot$ Jan K. Buitelaar $\cdot$ David Coghill $\cdot$ Ralf W. Dittmann · Kerstin Konrad • \\ Pietro Panei • Eric Rosenthal · Edmund J. Sonuga-Barke • Ian C. K. Wong
}

Received: 8 October 2012/ Accepted: 29 January 2013/Published online: 19 March 2013

(c) Springer-Verlag Berlin Heidelberg 2013

\begin{abstract}
To compile an inventory of European healthcare databases with potential to study long-term effects of methylphenidate (MPH) in patients with attention deficit hyperactivity disorder (ADHD). Potential databases were identified through expert opinion, the website of the European Network of Centres for Pharmacoepidemiology and Pharmacovigilance, and literature search. An online survey was conducted among database providers/coordinators to ascertain the databases' appropriateness for inclusion into
\end{abstract}

On behalf of the Attention deficit hyperactivity disorder drugs use chronic effects (ADDUCE) project, European Community's 7th framework programme project number 260576.

M. L. Murray $(\bowtie) \cdot$ S. Insuk · A. C. Neubert · I. C. K. Wong Centre for Paediatric Pharmacy Research,

University College London School of Pharmacy,

London, UK

e-mail: macey.murray@ucl.ac.uk

T. Banaschewski $\cdot$ R. W. Dittmann

Department of Child and Adolescent Psychiatry,

Medical Faculty Mannheim, Central Institute of Mental Health,

University of Heidelberg,

Mannheim, Germany

e-mail: tobias.banaschewski@zi-mannheim.de

R. W. Dittmann

e-mail: ralf.dittmann@zi-mannheim.de

\section{A. C. Neubert}

Department of Paediatric and Adolescent Medicine,

University Hospital Erlangen,

Erlangen, Germany

e-mail: antje.neubert@uk-erlangen.de

S. McCarthy

School of Pharmacy, University College Cork,

Cork, Ireland

e-mail: S.McCarthy@ucc.ie the inventory. It included questions about database characteristics, sample size, availability of information on drug exposure, clinical data and accessibility. Forty-two databases from 11 countries were identified and their coordinators invited to participate; responses were obtained for 22 (52.4\%) databases of which 15 record ADHD diagnoses. Eleven had sufficient data on ADHD diagnosis, drug exposure, and at least one type of outcome information (symptoms/clinical events, weight, height, blood pressure, heart rate) to assess MPH safety. These were Aarhus University Prescription Database, Danish National Birth Cohort (Denmark); German Health Interview and Examination Survey for Children and Adolescents; Health Search

\section{S. McCarthy}

Pharmacy Department, Cork University Hospital,

Cork, Ireland

\section{J. K. Buitelaar}

Department of Cognitive Neuroscience, Radboud University

Nijmegen Medical Centre, Donders Institute for Brain,

Cognition and Behaviour, Nijmegen, The Netherlands

e-mail: JB@psy.umcn.nl

D. Coghill

Division of Neuroscience, Medical Research Institute,

University of Dundee, Dundee, UK

e-mail: d.r.coghill@dundee.ac.uk

\section{K. Konrad}

Section of Child Neuropsychology, Department of Child and Adolescent Psychiatry, University Hospital Aachen, Aachen, Germany

e-mail: kkonrad@ukaachen.de

P. Panei

Department of Therapeutic Research and Medicines Evaluation, Istituto Superiore di Sanità, Rome, Italy

e-mail: pietro.panei@iss.it 
Database Thales, Italian ADHD Register, Lombardy Region ADHD Database (Italy); Avon Longitudinal Study of Parents and Children, General Practice Research Database, The Health Improvement Network, QResearch (UK) and IMS Disease Analyzer (UK, Germany, France). Of the 20 databases with no responses, information on seven from publications and/or websites was obtained; Pedianet and the Integrated Primary Care Information database were considered suitable. Many European healthcare databases can be used for multinational long-term safety studies of MPH. Methodological research is underway to investigate the feasibility of their pooling and analysis.

Keywords Database(s) - Methylphenidate . Attention deficit hyperactivity disorder (ADHD) . Drug safety $\cdot$ Paediatric

\section{Background}

As a first-line pharmacological therapy for attention deficit hyperactivity disorder (ADHD), methylphenidate (MPH) is widely prescribed in children and adolescents and to a lesser extent to adults. The efficacy of MPH in ADHD has been robustly demonstrated in randomised controlled trials with approximately $70 \%$ of children, adolescents and adults showing a therapeutic response [1]. Other effective drugs for ADHD are the potent psychostimulant dexamfetamine and atomoxetine, a selective noradrenaline reuptake inhibitor. Although the medications for ADHD are generally well-tolerated, commonly reported adverse effects include neurological effects (such as headache, insomnia), gastroenterological effects (loss of appetite, nausea and vomiting, abdominal pain), psychiatric effects

\section{E. Rosenthal}

Department of Paediatric Cardiology, Evelina Children's

Hospital, St Thomas' Hospital, London, UK

e-mail: eric.rosenthal@gstt.nhs.uk

\section{E. J. Sonuga-Barke}

Institute for Disorders of Impulse and Attention,

School of Psychology, University of Southampton,

Southampton, UK

e-mail: ejb3@soton.ac.uk

\section{E. J. Sonuga-Barke}

Department of Experimental Clinical and Health Psychology, Ghent University, Ghent, Belgium

\section{C. K. Wong}

Centre for Safe Medication Practice and Research, Department of Pharmacology and Pharmacy, Li Ka Shing

Faculty of Medicine, The University of Hong Kong,

Hong Kong SAR, China

e-mail: wongick@hku.hk (mood, anxiety) and chronic effects such as growth restriction and increases in blood pressure [2,3]. In order to control the acute and chronic adverse effects of medication, often patients on long-term ( $>1$ year) drug treatment have a structured interruption of treatment (known as a drug holiday). This allows monitoring to ensure medication is still effective, and assessment of whether the balance between adverse effects and therapeutic effects favours the continuation of treatment [3].

In 2006, there were safety concerns reported about the use of amfetamines and MPH as treatments for ADHD, specifically with respect to cardiovascular safety of these products [4]. In 2007, the European Commission requested a referral to the Committee for Medicinal Products for Human Use (CHMP) under Article 31 of Directive 2001/83/EC, as amended, for MPH because of safety concerns [5]. The CHMP concluded that insufficient was known about the long-term adverse effects of MPH on growth, sexual development, the neurological system, psychiatric states and the cardiovascular system, and further assessment is needed. In January 2009, the European Medicines Agency (EMA) concluded that the benefit-risk ratio of methylphenidate in the authorised indication remains favourable, but more data are needed on the longterm effects in children, adolescents and young adults [6]. In response to the CHMP's concerns, the ADDUCE (Attention deficit hyperactivity disorder drugs use chronic effects) research team was formed by a consortium of experts in the fields of ADHD, drug safety, neuro-psychopharmacology and cardiovascular research. The ADDUCE project, funded under the European Union's 7th Framework Programme, will use pharmacoepidemiological research methods to investigate the long-term adverse effects of MPH on growth, the neurological system (including cognition and motivation), psychiatric states and the cardiovascular system in children, adolescents and adults. The methodologies employed will be the acquisition and analysis of existing patient databases, a 2-year prospective cohort study of MPH-treated patients and two control groups, and a cross-sectional study in late adolescents and young adults. A methodological overview of the ADDUCE project is provided by the website (http:// adhd-adduce.org).

Electronic health care databases, comprising patient data, drug prescription data, patient outcomes and information on confounding variables, potentially provide valuable resources to examine associations between drug use and long-term adverse effects. A survey published in 2008 showed that many European healthcare databases had enormous potential for use in paediatric drug utilisation and safety studies [7]. The use of electronic health records was also recommended by the EMA when conducting postauthorisation drug utilisation and safety studies [8]. 
Previous studies have demonstrated that healthcare databases can be used to investigate certain adverse effects of MPH. Gau et al. used the National Health Insurance database (Taiwan) to assess the association between MPH use and psychiatric disorders in 2,109 children and adolescents with new onset ADHD between 1999 and 2003 matching 1:4 with non-ADHD controls. In this study, MPH use was associated with the occurrence of bipolar disorder (adjusted hazard ratio (HR), 4.1; $95 \%$ CI 1.7, 9.7, $p<0.05$ ) [9]. McCarthy et al. aimed to estimate the mortality rates associated with stimulant and non-stimulant treatment prescription using the UK General Practice Research Database (GPRD). Compared with the general population, there was a 162-fold increased risk of completed suicide in patients aged 11-14 years using psychostimulants or atomoxetine (standardized mortality ratio: 161.91 [95 \% CI 19.61, 584.88]) [10]. Recently, four large US health-plan databases of insurance claims were combined to assess the use of ADHD drugs and the risk of serious cardiovascular events (sudden cardiac death, myocardial infarction, stroke) in children and young adults [11]. A total of 81 serious cardiovascular events were confirmed from over 2.5 million person-years of follow-up giving an incidence of 3.1 events per 100,000 person-years in the study cohort. Among current users of ADHD drugs, there was no increased risk of serious cardiovascular events when compared with non-users (adjusted HR, 0.75; $95 \%$ CI $0.31,1.85)$, and there was no evidence of increased risk for methylphenidate (adjusted HR, 0.96; $95 \%$ CI 0.31, 2.97). Another study of claims data (Medicaid) from $28 \mathrm{US}$ states found that the treatment of children aged 3-18 years with MPH or mixed amfetamine salts was not significantly associated with an increased short-term risk of severe cardiac events [12]. However, both US studies were unable to assess the long-term safety of stimulant treatment due to their short follow-up of 2 years [11, 12].

On the basis of these examples, we judged that analysis of existing health care databases might be useful to study the association between MPH use and long-term adverse events. Although this might not be possible for all adverse events of interest (e.g. sleep abnormalities), such databases may provide important health information relevant for the systematic study of side effects. However, many studies performed in Europe have been limited in their power and scope by the use of a single data source. Cooper et al. [11] demonstrated the value of using multiple existing databases in the US to obtain large sample sizes to study the safety of ADHD drugs; adopting a similar approach in Europe may be valuable if the issues concerning the pooling of such databases could be overcome. Our previous work has shown this to be feasible [13-16]. Hence, the aim of this study is to compile an inventory of existing European databases which can be used to study the effects of longterm MPH use in patients with ADHD.

\section{Methods}

There were a number of steps taken to achieve our aim.

First, a list of all known potentially relevant European databases with individual patient information was collated. A range of different methods were used to identify eligible databases: from those listed on the website of the European Network of Centres for Pharmacoepidemiology and Pharmacovigilance (ENCePP), a systematic review of the published literature (including conference proceedings [17]) and finally, by nominations from members of the ADDUCE Consortium.

Second, a questionnaire comprising 33 questions to collect detailed database information was designed (by SI, TB, MLM, SM, AN and ICKW) and implemented using a web-based data collection tool (SurveyMonkey ${ }^{\mathrm{TM}}$ ). A request to complete the questionnaire survey was sent to the providers/coordinators of the identified databases. Information collected on each database comprised general information on the database (name, country), a description of the nature of the database (e.g. longitudinal/patient record database, disease registry, cross-sectional, observational data survey), characteristics and sample size (such as number of investigators, database starting date, and number of patients), availability of data on the exposure to medication and on symptoms and clinical events and accessibility. Examples of questions are "Is information available on ADHD diagnosis?"; "Which of the following data are recorded in the database? Weight, height, blood pressure, heart rate" and "What system is used to code diagnoses?"

Third, databases were categorised with respect to their potential suitability for investigating the long-term safety of MPH based on the availability of individual patient information. Our criteria were based on the basic data elements that are required for pharmacoepidemiologic research using healthcare databases [18]. To be useful for the investigation of the long-term safety of MPH use for ADHD, databases had to record information about the following clinical aspects of individual patients: ADHD diagnosis, MPH exposure (dose and duration), exposure to other medications, potential adverse outcomes (such as effects on height and weight, blood pressure, heart rate) and other symptoms/clinical events. Furthermore, information on the structure and standardisation of data, costs to access the database, completeness of clinical and drug information and previous applications in research or validation studies were considered. The ability to combine with data from other sources was also assessed based on whether 
the database used unique patient identifiers (to allow for record linkage) and coding systems for diagnoses, clinical events and medications prescribed.

Last, detailed information of all databases without survey responses were sought from publications and the websites of their data providers/coordinators, where possible information collated were based on that requested in the survey questions. The databases were then assessed for their potential suitability using similar criteria to those used above.

\section{Results}

Response to the survey

Forty-two databases from 11 European countries were identified and their providers/coordinators were invited to participate in the survey (Fig. 1). Responses were obtained from $22(52.4 \%)$ database coordinators/providers in seven European countries (Table 1). Seven of these 22 databases did not contain information on ADHD diagnosis; therefore, 15 databases were included in the detailed assessment. Table 2 provides detailed information of the participating databases. Only one database had an incomplete response to the survey (Generation R study), however, it was possible to obtain some of the missing details from the literature $[19,20]$. There was information on over 4.5 million children and adolescents in these 15 databases (of which just over 23,000 from six databases are reported to have ADHD), this is an overestimate due to the possibility that patients and/or their clinicians can contribute information to more than one database. For example, there is an overlap between GPRD and The Health Improvement Network (THIN), where $66 \%$ of contributing practices in THIN also contribute to GPRD between 2001 and 2008 [21].

\section{Type of database}

Most of the selected databases are longitudinal/patient record databases $(n=11)$. Two are ADHD specific patient cohorts (Lombardy Region ADHD Database and the Italian ADHD Register). One is a prescription information database (Aarhus University Prescription Database) and one is a cross-sectional, observational data survey (German Health Interview and Examination Survey for Children and Adolescents; KiGGS). Three databases could be linked to various other registries through unique patient identifiers (Aarhus University Prescription Database, Swedish National Health Data Registers and the National Psychiatric

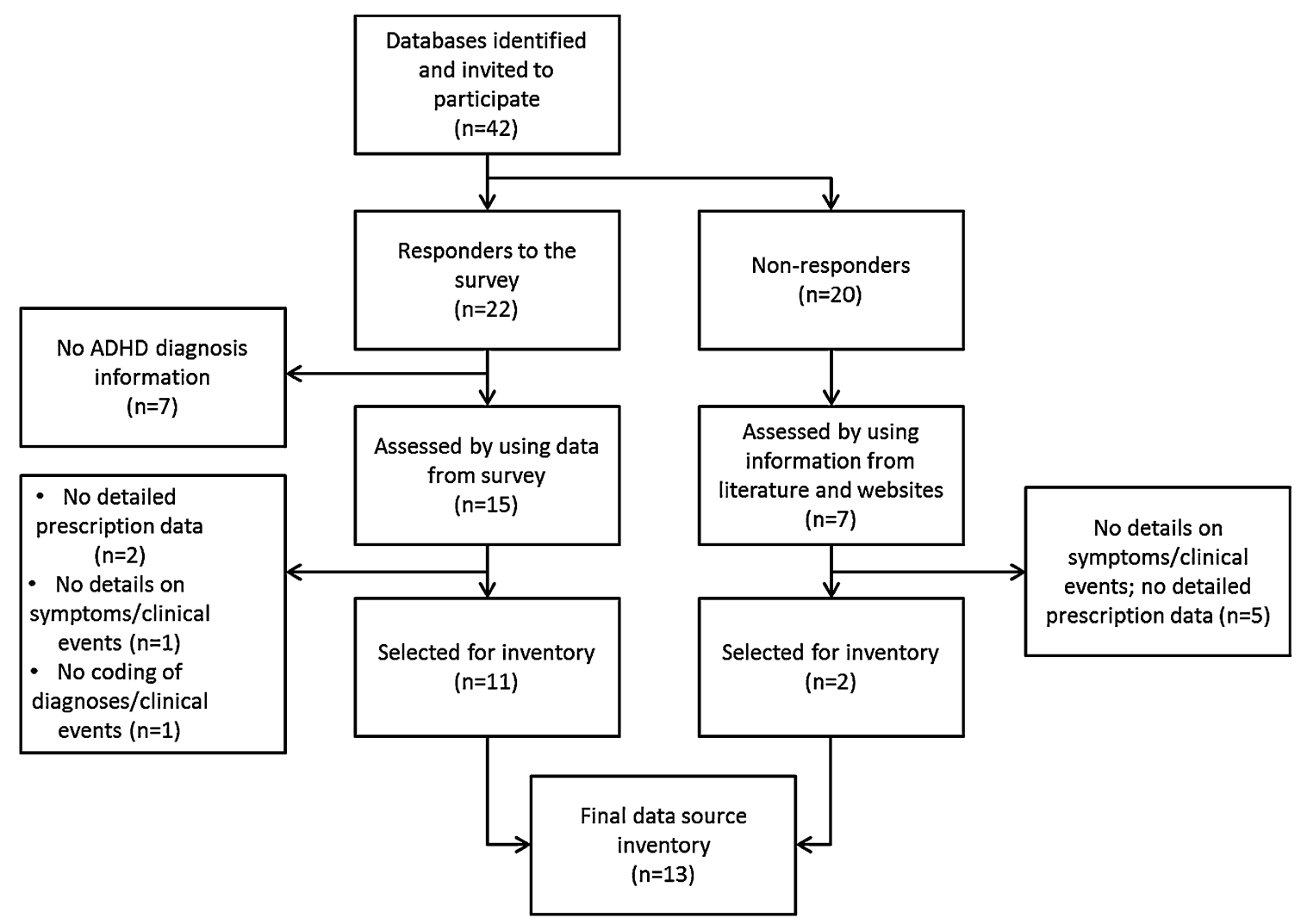

Fig. 1 Survey and database assessment schematic flowchart 
Table 1 Databases identified and invited to participate in the survey

\begin{tabular}{|c|c|c|c|c|c|}
\hline Country & $\begin{array}{l}\text { Purpose } \\
\text { of database }\end{array}$ & Database & Website & Response & $\begin{array}{l}\text { Information } \\
\text { from websites } \\
\text { and literature }\end{array}$ \\
\hline Denmark & PM & National Psychiatric Central Register & $\begin{array}{l}\text { www.psykiatriskforskning.dk/ } \\
\text { research/central-research-register/ }\end{array}$ & Yes & No \\
\hline Denmark & PM/Admin & $\begin{array}{l}\text { Odense Pharmacoepidemiological } \\
\text { Database }\end{array}$ & www.sdu.dk & Yes & No \\
\hline Denmark & PM/Admin & Aarhus University Prescription Database & $\begin{array}{l}\text { kea.au.dk/en/informaticsand } \\
\text { statistics/researchdatabases/ } \\
\text { theprescriptiondatabases/ }\end{array}$ & Yes & No \\
\hline Denmark & $\mathrm{RC}$ & $\begin{array}{l}\text { The Danish National Birth Cohort } \\
\text { (DNBC) }\end{array}$ & www.dnbc.dk/ & Yes & No \\
\hline Finland & PM/Admin & Prescription register & www.kela.fi & No & Yes \\
\hline Finland & $\mathrm{RC}$ & $\begin{array}{l}\text { The Finnish Northern Finland Birth } \\
\text { Cohort (NFBC) } 1986 \text { study }\end{array}$ & kelo.oulu.fi/NFBC/ & No & Yes \\
\hline Germany & $\mathrm{RC}$ & $\begin{array}{l}\text { The German Health Interview and } \\
\text { Examination Survey for Children and } \\
\text { Adolescents (KiGGS) }\end{array}$ & www.rki.de & Yes & No \\
\hline Germany & $\mathrm{PM}$ & $\begin{array}{l}\text { The German Population Based } \\
\text { Long-Term Follow-up of ADHD }\end{array}$ & www.bips.uni-bremen.de & No & Yes \\
\hline Italy & $\mathrm{PM}$ & Pedianet & www.pedianet.it/ & No & Yes \\
\hline Italy & PM & $\begin{array}{l}\text { Sistema Informativo Sanitario Regionale } \\
\text { Database-FVG region }\end{array}$ & www.regione.fvg.it & No & No \\
\hline Italy & $\mathrm{PM}$ & $\begin{array}{l}\text { Health Search Database Thales_CSD } \\
\text { LPD (HSD) }\end{array}$ & www.healthsearch.it/ & Yes & No \\
\hline Italy & PM & Tuscany Regional database & www.arsanita.toscana.it & No & No \\
\hline Italy & $\mathrm{PM}$ & Lombardy Regional ADHD database & $\begin{array}{l}\text { givitiweb.marionegri.it/Centres/ } \\
\text { Public/ADHD/Default.aspx }\end{array}$ & Yes & No \\
\hline Italy & $\mathrm{PM}$ & ARNO Observatory & $\begin{array}{l}\text { osservatorioarno.cineca.org/ } \\
\text { arnoeng.htm }\end{array}$ & No & No \\
\hline Italy & $\mathrm{PM}$ & The National ADHD Registry & www.farmaco-iss.org/ & Yes & No \\
\hline Netherlands & $\mathrm{PM}$ & $\begin{array}{l}\text { Integrated Primary Care Information } \\
\text { Database (IPCI) }\end{array}$ & www.ipci.nl & No & Yes \\
\hline Netherlands & PM & PHARMO-Record-Linkage-System & www.pharmo.nl & Yes & No \\
\hline Netherlands & PM & InterAction database & www.iadb.nl & Yes & No \\
\hline Netherlands & $\mathrm{RC}$ & The Dutch KOALA Birth Cohort Study & www.koala-study.nl & Yes & No \\
\hline Netherlands & $\mathrm{RC}$ & The Dutch TRAILS study & & No & No \\
\hline Netherlands & $\mathrm{RC}$ & The Dutch Generation R study & www.generationr.nl/ & Yes & No \\
\hline Norway & PM & The Norwegian Prescription Database & www.norpd.no/ & Yes & No \\
\hline Portugal & $\mathrm{RC}$ & $\begin{array}{l}\text { Centro de Estudos e Avaliação em Saúde } \\
\text { (Centre for Health Studies and } \\
\text { Evaluation) (CEFAR) }\end{array}$ & & No & No \\
\hline Sweden & $\mathrm{PM}$ & Swedish Medical Birth Register & www.socialstyrelsen.se & Yes & No \\
\hline Sweden & PM & Swedish National Health Data Registers & www.socialstyrelsen.se & Yes & No \\
\hline Sweden & $\mathrm{RC}$ & $\begin{array}{l}\text { The Swedish All Babies in Southeast } \\
\text { Sweden }\end{array}$ & www.abis-studien.se/ & No & No \\
\hline Spain & PM & $\begin{array}{l}\text { Base de datos para la Investigacion } \\
\text { Farmacoepidemiologica en Atencion } \\
\text { Primaria (BIFAP) }\end{array}$ & www.bifap.org/ & No & No \\
\hline UK & $\mathrm{PM}$ & $\begin{array}{l}\text { General Practice Research Database } \\
\text { (GPRD) (now part of Clinical Practice } \\
\text { Research Datalink) }\end{array}$ & www.cprd.com/ & Yes & No \\
\hline UK & $\mathrm{PM}$ & $\begin{array}{l}\text { The Health Improvement Network Data } \\
\text { (THIN) }\end{array}$ & csdmruk.cegedim.com/ & Yes & No \\
\hline UK & PMS & Prescription Event Monitoring (PEM) & www.dsru.org/pem & Yes & No \\
\hline UK & Admin & Prescription Pricing Authority (PPA) & $\begin{array}{l}\text { www.nhsbsa.nhs.uk/ } \\
\text { PrescriptionServices.aspx }\end{array}$ & No & No \\
\hline
\end{tabular}


Table 1 continued

\begin{tabular}{|c|c|c|c|c|c|}
\hline Country & $\begin{array}{l}\text { Purpose } \\
\text { of database }\end{array}$ & Database & Website & Response & $\begin{array}{l}\text { Information } \\
\text { from websites } \\
\text { and literature }\end{array}$ \\
\hline UK & PM & QResearch & www.qresearch.org/ & Yes & No \\
\hline UK & PM & $\begin{array}{l}\text { Scottish Programme for Improving } \\
\text { Clinical Effectiveness in Primary Care } \\
\text { (SPICE) formerly known as GPASS } \\
\text { (General Practice Administration } \\
\text { System for Scotland) }\end{array}$ & $\begin{array}{l}\text { www.abdn.ac.uk/iahs/uploads/ } \\
\text { files/PCI.pdf }\end{array}$ & No & No \\
\hline UK & PM & Medicines Monitoring Unit (MEMO) & www.dundee.ac.uk/memo/ & No & No \\
\hline UK & $\mathrm{RC}$ & $\begin{array}{l}\text { The Avon Longitudinal Study of Parents } \\
\text { and Children (ALSPAC) }\end{array}$ & www.bristol.ac.uk/alspac/ & Yes & No \\
\hline UK & $\mathrm{RC}$ & The 1970 British Cohort Study & www.cls.ioe.ac.uk/bcs70 & No & Yes \\
\hline UK & $\mathrm{RC}$ & The Millennium Cohort Study & www.cls.ioe.ac.uk/mcs & No & Yes \\
\hline UK & $\mathrm{RC}$ & $\begin{array}{l}\text { The } 2004 \text { British Child and Adolescent } \\
\text { Mental Health Survey }\end{array}$ & & No & No \\
\hline UK & $\mathrm{RC}$ & The Scottish SEATON Study & www.abdn.ac.uk/seatonstudy/ & Yes & No \\
\hline European & $\mathrm{RC}$ & $\begin{array}{l}\text { The ADHD Observational Research in } \\
\text { Europe }\end{array}$ & & No & No \\
\hline European & $\mathrm{RC}$ & $\begin{array}{l}\text { The International Muti-Center ADHD } \\
\text { Genetics (IMAGE) Project }\end{array}$ & & No & No \\
\hline $\begin{array}{l}\text { UK, France, } \\
\text { Germany }\end{array}$ & PM & IMS Disease Analyzer (IMS DA) & www.imshealth.com/ & Yes & No \\
\hline
\end{tabular}

$P M$ Patient management and/or disease surveillance, $R C$ Research cohort, Admin administrative database for reimbursement and/or renumeration of prescriptions, $P M S$ post-marketing surveillance

Central Register). The purpose of data collection of the majority of databases was for patient management and disease surveillance $(n=10)$; the remaining five are research cohorts: Danish National Birth Cohort (DNBC), KiGGS, Generation R Study, Dutch Child, Parent and health: Lifestyle and Genetic constitution (KOALA) Birth Cohort Study and Avon Longitudinal Study of Parents and Children (ALSPAC).

\section{Drug exposure}

Almost all databases contain information on prescribed medicines; Generation R Study does not collect details on prescriptions or drug exposure. One (Lombardy Region ADHD Database) has information on MPH and atomoxetine only. Most $(n=14)$ include information on medical diagnosis and the indication for prescription drugs. Four databases (National Psychiatric Central Register, Generation R study, Swedish National Health Data Registers, and ALSPAC) contain limited information on dosage and duration of treatment. The Anatomical Therapeutic Chemical classification system (ATC) is commonly used to classify medications; 10 of the 15 databases use this coding scheme [22, 23]. Multilex is a UK drug terminology system used to classify medications and is used in the GPRD and THIN databases. Only one database (KOALA) currently does not use a medication coding system.

\section{Clinical outcomes}

Full clinical data (symptoms and clinical events, weight and height, blood pressure and heart rate) are available in eight databases [KiGGS, Italian ADHD Register, Lombardy Region ADHD register, KOALA, ALSPAC, GPRD, THIN, and IMS Disease Analyzer (IMS DA)]. The International Classification of Diseases 10th Revision (ICD-10) is used as the diagnoses/clinical event coding system in six databases (Aarhus University Prescription Database, DNBC, National Psychiatric Central Register, Swedish National Health Data Registers, ALSPAC, and IMS DA) [24]. Read Clinical Terms (a UK hierarchical classification system) is used in four UK databases (GPRD, THIN, QResearch, and IMS DA). One database, Health Search Database Thales (HSD), uses ICD-9 to code diagnoses and clinical events.

\section{Other variables}

The diagnostic process for ADHD and hyperkinetic disorder includes the recognition of specific behavioural and attentional symptoms per criteria of either the DSM-IV (Diagnostic and Statistical Manual of Mental Disorders, 4th edition) [25] or ICD-10. However, these symptoms are also found in disorders other than ADHD [26, 27]. Therefore, information on whether the ADHD diagnosis 


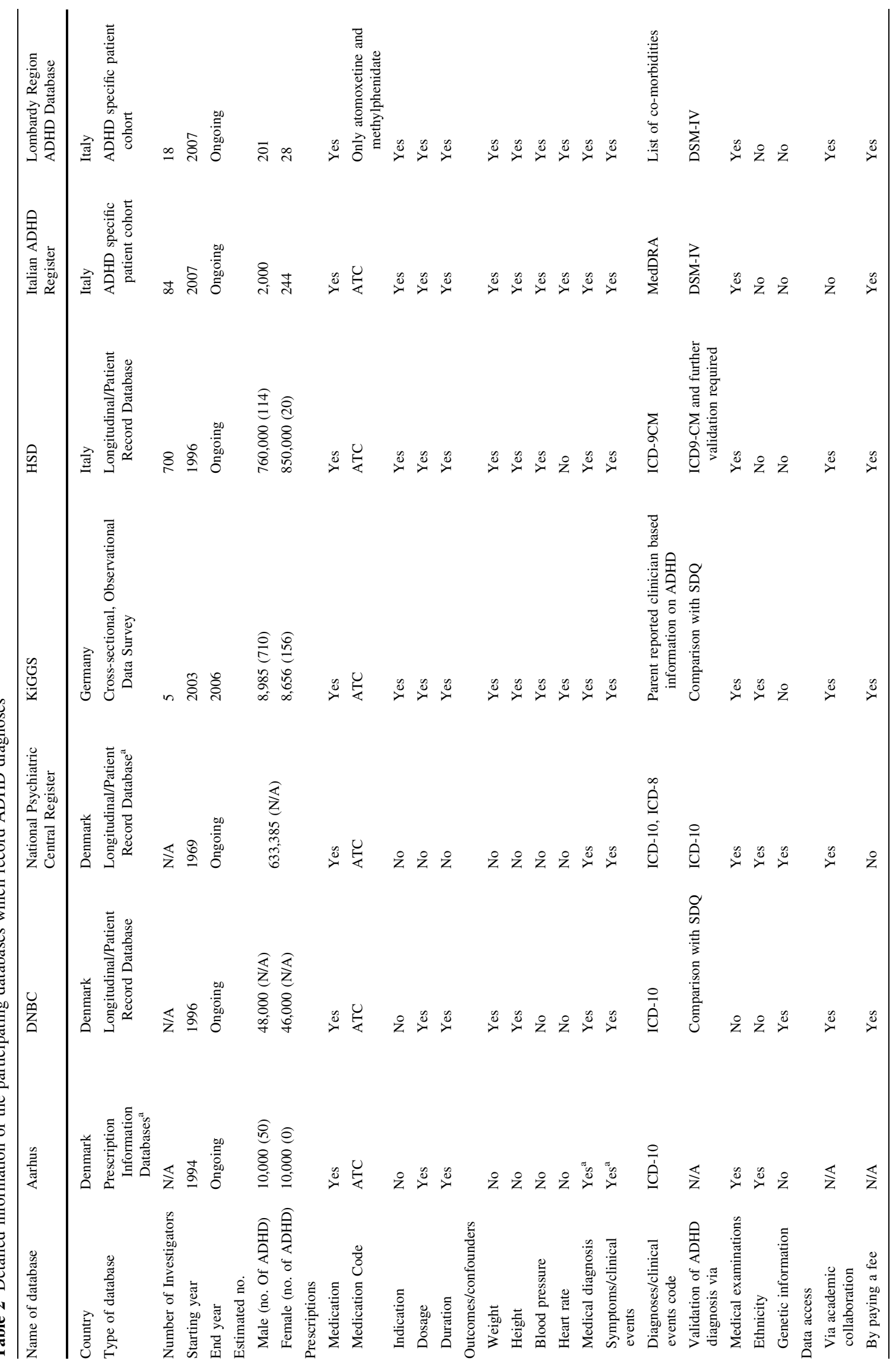




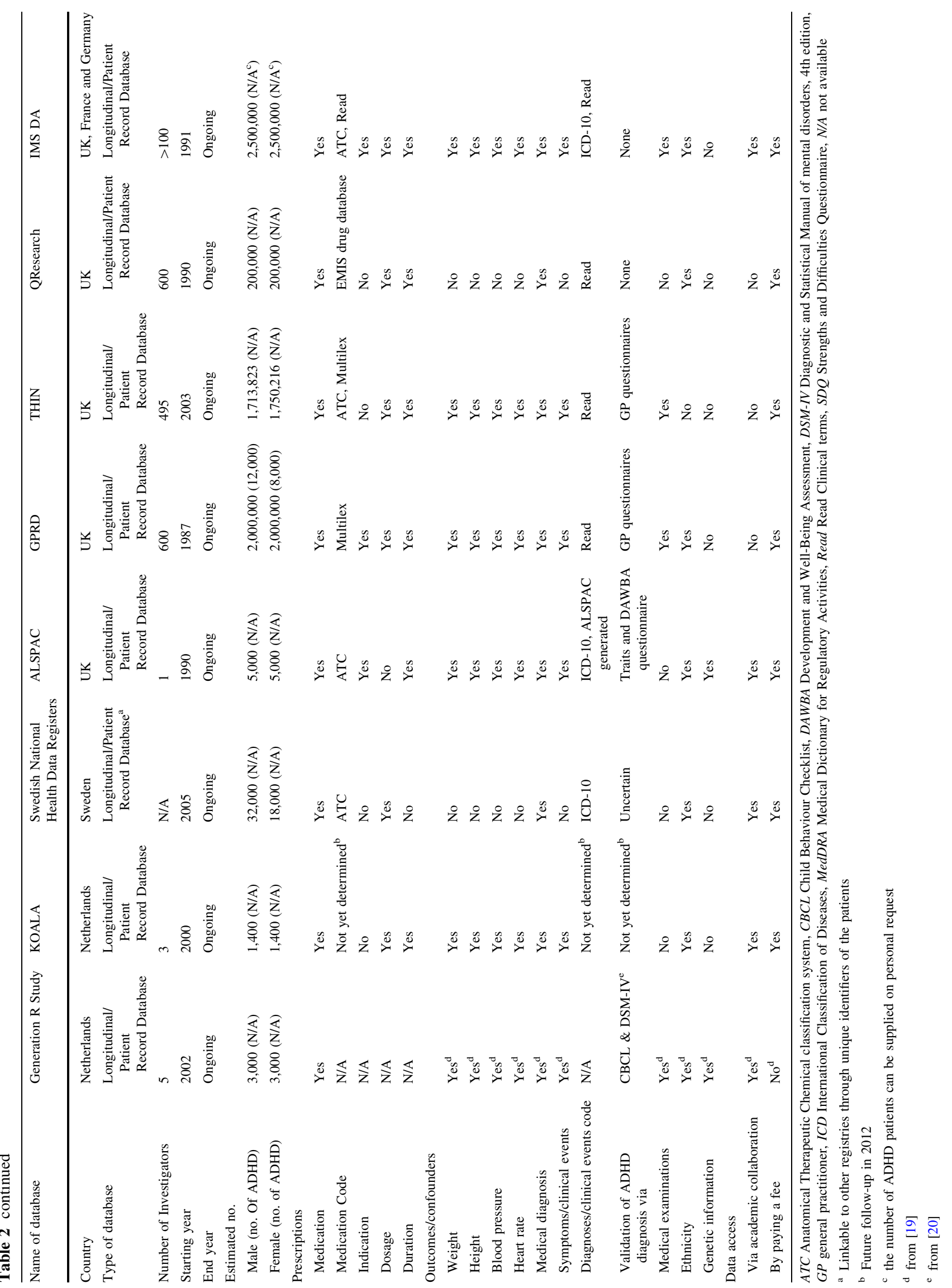


had been validated is important. For two databases (Italian ADHD Register and Lombardy Region ADHD Database), clinicians use DSM-IV criteria to confirm diagnoses. In DNBC and KiGGS, ADHD diagnosis is supported by the scores from Strengths and Difficulties Questionnaire (SDQ) [28], which has a scale measuring ADHD symptoms. Questionnaires to general practitioners (GPs) can be used to obtain further information on diagnosis in the GPRD and THIN databases.

Nine databases include information on ethnicity. Three databases (DNBC, National Psychiatric Central Register, and ALSPAC) also collect genetic information.

\section{Previous applications of databases in the field of research in paediatrics and/or $A D H D$}

The Italian ADHD Register has been previously used in studies on medication safety in ADHD patients [29-31]. The GPRD and THIN databases have been used to study the safety and use of ADHD drug treatment [10, 32, 33]. Data from KiGGS has been used in a number of paediatric studies, including those investigating the prevalence of mental health disorders, such as ADHD and drug treatment [34, 35]. ALSPAC has been widely studied and has numerous publications in paediatric research but none in ADHD.

\section{Data access}

All databases apart from one can be accessed either by paying a fee and/or via academic collaboration. Nine of them (DNBC, National Psychiatric Central Register, KiGGS, HSD, Lombardy Region ADHD Database, KOALA, Swedish National Health Data Registers, ALSPAC, IMS DA) can be accessed via academic collaboration. The means to access the Aarhus University Prescription Database was not reported in the survey, but the literature states project-specific permission from the Danish Data Protection Agency is required and any data-linkage studies (which would be necessary to obtain outcome data) need approval from the Danish National Board of Health [36].

Assessment of non-responding databases

We obtained information on seven additional databases whose coordinators did not reply to the survey. These were Prescription Register (Finland), The Finish Northern Finland Birth Cohort (NFBC) 1986 study, The German Population Based Long-Term Follow-up of ADHD, Pedianet (Italy), Integrated Primary Care Information Database (IPCI; Netherlands), The 1970 British Cohort Study and The Millennium Cohort Study (UK). These databases were appraised using the same criteria as above with information obtained from database websites and published literature (Table 3).

\section{Type of database}

Three of these seven databases are longitudinal/patient record databases (the German Population Based LongTerm Follow-up of ADHD, Pedianet and IPCI). Three are longitudinal birth cohorts (NFBC, the 1970 British Cohort Study, and The Millennium Cohort Study). Only one database is a prescription information database [Prescription Register (Finland)].

\section{Drug exposure}

Only two of the databases include information on indication of prescription and/or medical diagnosis (Pedianet and IPCI). Information on dosage and duration of prescription is available in Pedianet and IPCI, and both use the WHO ATC classification system [22].

\section{Clinical outcomes}

Information on weight and height is found in Pedianet, IPCI, the 1970 British Cohort Study and the Millennium Cohort Study. Two databases provide information on medical diagnosis and symptoms/clinical events (Pedianet and IPCI). Only IPCI classifies diagnoses/clinical events using the International Classification of Primary Care (ICPC) code [37].

\section{Other variables, previous applications in research} and data access

Due to limited information on these databases, the availability of data on confounding variables and data accessibility cannot be assessed. There is one study using Pedianet to investigate the safety of paediatric drugs [38]. No studies of paediatric drug safety using the IPCI database could be identified in the literature. However, both databases have been previously used to study paediatric drug use [13-16]. A study describing the incidence and prevalence of ADHD and drug treatment for ADHD using The German Population Based Longterm Follow-Up of ADHD database has been conducted [39].

Selection of data source inventory

According to our criteria for suitability, 11 of the 15 responding databases were considered to have potential value for the long-term safety evaluation of MPH. These are Aarhus University Prescription Database, DNBC, 


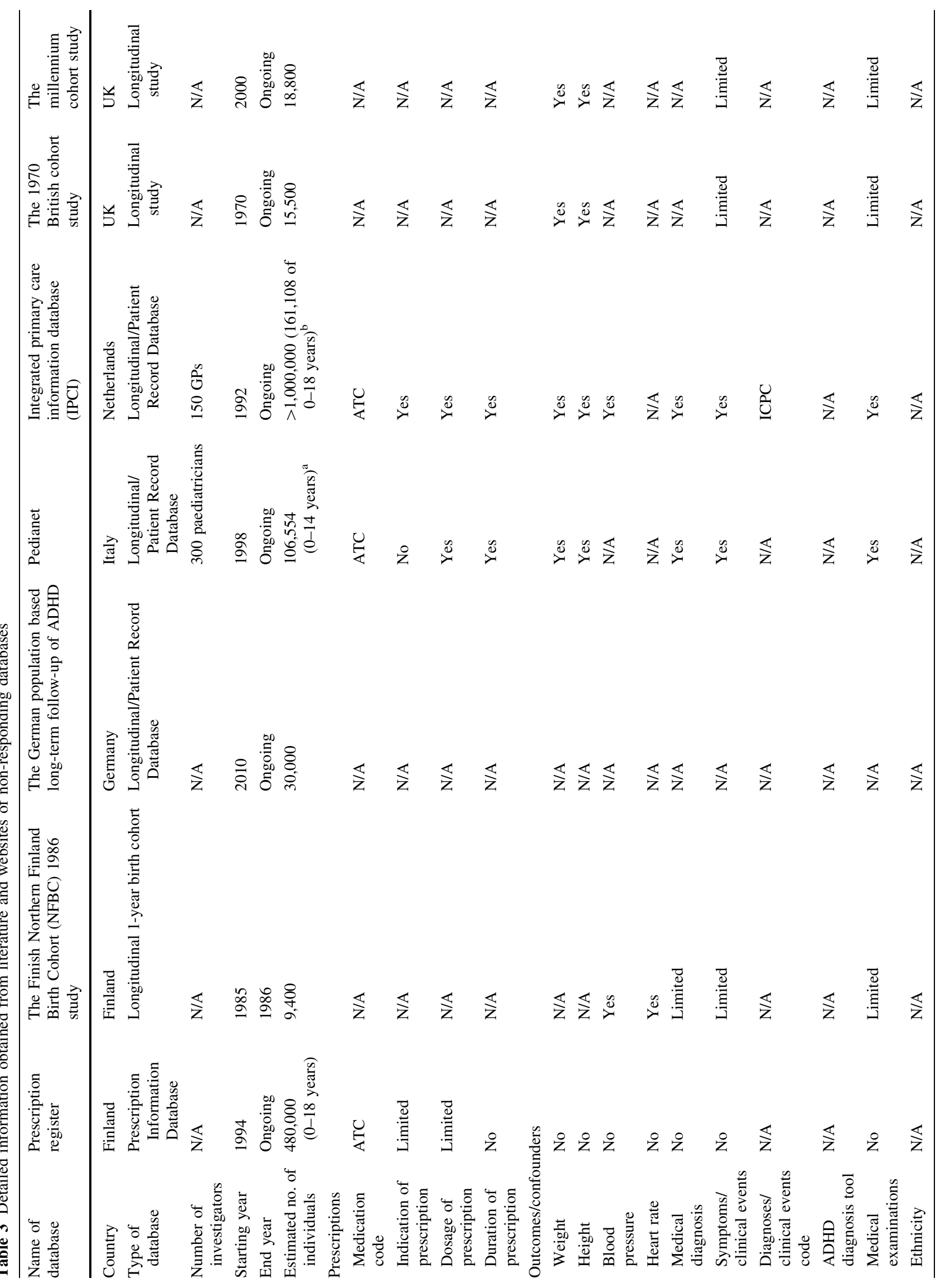




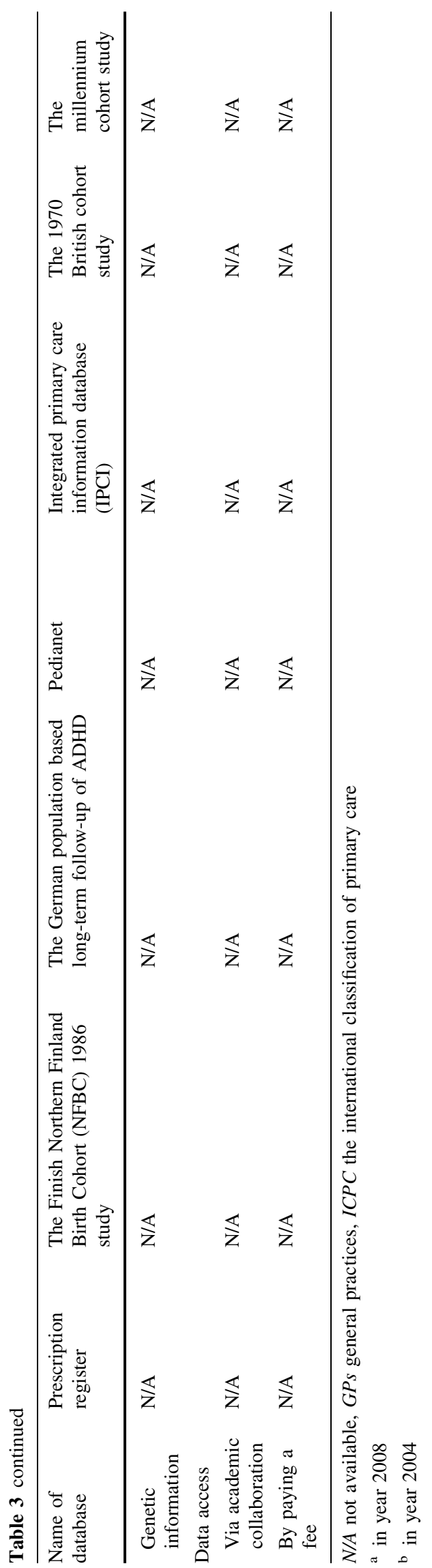

KiGGS, HSD, Italian ADHD Register, Lombardy Region ADHD Database, ALSPAC, GPRD, THIN, QResearch and IMS DA. Of the non-responding databases, Pedianet and IPCI were considered potentially suitable. Hence, 13 databases were included in our data source inventory.

\section{Discussion}

From our survey, we identified 13 sources of electronic health care records in Europe which have potential value in investigating the long-term effects of MPH treatment in patients with ADHD. These databases were selected because they record basic data elements required to conduct drug safety studies; these include validated ADHD diagnosis (or at least the ability to confirm diagnosis), other diagnoses and clinical events, exposure to MPH, and exposure to any other medications and potential adverse clinical outcomes. These data are rich resources, easily accessible, sourced from real-life practice, with the potential to provide large study populations for the longterm safety evaluation of MPH. Many are longitudinal in nature, which is essential for the long-term follow-up of patients.

However, it is generally recognised that existing sources of data (including those we have identified) may have several limitations such as selection bias, lack of control or comparison group, missing data (or limited detailed clinical information) [18], small sample sizes and issues of quality control in data collection. For example, the selection of an un-medicated group of ADHD patients from the 13 data cohorts may be challenging due to the small numbers of patients that exist (and would also affect prospective cohort studies). Some data may be unrecorded because the purpose of the database did not require it, such as details of pubertal maturation, specific psychiatric rating scales, measurements of brain function and activity (EEG, fMRI), or risk factors such as developmental history, parental history of medical and psychiatric problems and life events. Other data may not be routinely entered at specific time intervals (e.g. height, weight, blood pressure, heart rate). Missing data may restrict the ability of some data sources to be used to study specific long-term effects (such as developmental or psychiatric effects), or even threaten the reliability and validity of results, especially if confounding variables are unavailable. Misclassified diagnoses or outcomes can also affect the validity of a study. The issue of small sample sizes could be overcome if data are pooled to form larger cohorts. These issues are not pertinent to all of the selected data sources in our inventory, but they all should be carefully considered (and addressed) when selecting data sources for our drug safety research. 
After consideration of these general limitations, the ADDUCE Consortium proposed that high quality data should be collected in a large prospective cohort study of patients with ADHD and their controls. This cohort study would collect specific information at set time points on efficacy measures of MPH, growth, coordination, psychiatric effects (using rating scales such as DAWBADevelopmental and Well-being Assessment modules), neurological effects (rating scales, measures of brain function and activity), as well as patient demographics, family and personal medical, psychiatric and medication histories and physical examinations (including cardiac examinations). Much of these data are not recorded in the existing data sources of our inventory. However, there are also limitations to primary data collection of a large prospective cohort; it is time- and resource-consuming, and recruitment of a sufficiently large sample size to allow the study of rare effects of MPH may be difficult. Hence studies of large existing databases (single or pooled) in our inventory would complement those of the prospective cohort.

There are opportunities to exploit the databases that we have identified in our inventory; in particular, the combination of healthcare databases can potentially generate sample sizes and statistical power for large-scale drug safety studies [7]. European colleagues have recently pooled eight existing electronic healthcare databases covering four countries to generate an early signal detection system by creating a database platform using a common data framework (EU-ADR) [40]. The different clinical terminologies of the databases (e.g. Read Clinical Terms, ICD-9) can be mapped using a biomedical terminology integration system, Unified Medical Language System ${ }^{\circledR}$. This generated a study population of almost 20 million individuals with just under 60 million person-years of data. Five of these databases are included in our inventory (Aarhus University Prescription Database, HSD, QResearch, Pedianet and IPCI) [40]. However, the amalgamation of existing databases is complex and goes beyond issues of data structures and sources. There are ethical issues concerning the processing of anonymised healthcare data and national diversity in healthcare provision and practice [7, 40]. Also, some of the limitations described above such as the issue of data quality still remain, which affect the choice of analytical methods. Database providers may wish to improve the quality and completeness of recording by the end-user and increase the availability of more specific detailed clinical information (such as the results of diagnostic tests) [18] to enhance the research value of their databases. Despite the complexity of such a task, the EU-ADR project [40] and other studies [11] demonstrate that combining diverse databases of heterogeneous populations is feasible for drug safety research, with vast potential for further work.

\section{Conclusion}

There are 13 European databases of birth cohorts or electronic healthcare records included in the ADDUCE data inventory, which have potential value individually or pooled for the evaluation of the long-term safety of MPH treatment in patients with ADHD. They are rich sources of data from real-life settings and easily accessible. However, there are limitations in utilising existing sources of data including small sample sizes, missing data and poor data quality. The pooling of existing data sources presents opportunities for large-scale safety studies of MPH in the future; its feasibility is currently under investigation but data quality and analysis, ethical issues and national differences in healthcare provision need to be considered.

Acknowledgments The authors thank the database providers and coordinators for participating in the survey. The project was funded under the European Community's 7th framework programme project number 260576: ADDUCE (Attention Deficit Hyperactivity Disorder Drugs Use Chronic Effects).

Conflict of interest Mr. Insuk, Dr. Neubert and Dr. Panei declare they have no conflicts of interest. Dr. Murray received research funding from Shire and Pfizer. The present work is unrelated. Prof. Banaschewski served in an advisory or consultancy role for Bristol Myers-Squibb, Develco Pharma, Lilly, Medice, Novartis, Shire and Vifor Pharma. He received conference attendance support and conference support or received speaker's fee from Lilly, Janssen McNeil, Medice, Novartis, and Shire. He has been involved in clinical trials conducted by Lilly and Shire. The present work is unrelated to the above grants and relationships. Prof. Buitelaar has been in the past 3 years a consultant to/member of advisory board of/and/or speaker for Janssen Cilag BV, Eli Lilly, Bristol-Myer Squibb, Schering Plough, UCB Pharma, Shire, Novartis and Servier. He is not an employee of any of these companies, and not a stock shareholder of any of these companies. He has no other financial or material support, including expert testimony, patents and royalties. Dr. McCarthy received research funding from Shire. The present work is unrelated. Prof. Dittmann is a former employee of Lilly Deutschland and now holds the Eli Lilly Endowed Chair of Paediatric Psychopharmacology at the Central Institute of Mental Health, Medical Faculty Mannheim, University of Heidelberg, Germany. He also holds Eli Lilly \& Co. shares. He received research grants from the European Union, the US NIMH, the German Research Association (DFG), Ministry of Research/Education (BMBF), regulatory agency (BfArM), companies Ferring, Janssen-Cilag, Lilly and Shire, travel support and speaker honoraria from Lilly and Shire. Dr. Rosenthal has received conference attendance support or received speaker's fees from Shire. The present work is unrelated. Prof. Sonuga-Barke has served in a consultancy role and on the speaker boards of Shire and UCB Pharma. He received research support from Janssen Cilag, Shire, Qbtech, Flynn Pharma and served on the Advisory Board of Shire, Flynn Pharma, UCB Pharma, Astra Zeneca. He also received conference support from Shire. The present work is unrelated to the above grants and relationships. Prof. Wong was a member of the National Institute for Health and Clinical Excellence (NICE) ADHD Guideline Group and the British Association for Psychopharmacology ADHD guideline group. He has received research grants from various pharmaceutical companies; including Shire. He has given talks at educational events sponsored by Janssen-Cilag and Eli-Lilly and acted as an advisor to Shire. The present work is unrelated to the above grants and 
relationships. All authors declared that they have no financial interests that may be relevant to the submitted work.

\section{Appendix: Adduce consortium}

D. Coghill, S. Inglis, J. Wyatt (University of Dundee, UK), I.C.K. Wong (University of Hong Kong, China), J.K. Buitelaar, J. Glennon (Radboud University Nijmegen, the Netherlands), T. Banaschewski, R.W. Dittmann (Central Institute of Mental Health, Medical Faculty Mannheim, University of Heidelberg, Germany), A.C. Neubert (Department of Paediatric and Adolescent Medicine, University Hospital Erlangen, Germany), M.L. Murray (University College London School of Pharmacy, UK), C. Hollis, K. Sayal, E. Liddle, M. Lacey (University of Nottingham, UK), K. Konrad, H. Krinzinger (Section of Child Neuropsychology, Department of Child and Adolescent Psychiatry, University Hospital Aachen, Germany), S. McCarthy (University College Cork, Ireland), M. Danckaerts (Department of Child and Adolescent Psychiatry, University of Leuven, Belgium), A. Zuddas, S. Carucci, M. Piredda (Child Neuropsychiatry, Department of Neuroscience, University of Cagliari, Italy), P. Panei (Department of Therapeutic Research and Medicines Evaluation, Istituto Superiore di Sanità, Rome, Italy), B. Falissard (INSERM, Paris, France), J. Sergeant (EUNETHYDIS: European Network for Hyperkinetic Disorders, the Netherlands), J. Gadoros, P. Garas (Vadaskert Child and Adolescent Psychiatry Hospital and Outpatient Clinic, Budapest, Hungary), S. Conroy, J. Winslade (Therakind, London, UK), E. Rosenthal (Evelina Children's Hospital, Guy's and St Thomas' Hospital NHS Foundation Trust, London, UK), E.J. Sonuga-Barke, H. Kovshoff (University of Southampton, UK), P. Asherson, C. Murphy (Institute of Psychiatry, King's College London, UK), S. Evans (London School of Hygiene and Tropical Medicine, UK), A. Bilbow (ADDISS, London, UK).

\section{References}

1. Faraone SV, Biederman J, Spencer T, Wilens T, Seidman LJ, Mick E, Doyle AE (2000) Attention-deficit/hyperactivity disorder in adults: an overview. Biol Psychiatry 48(1):9-20

2. Graham J, Coghill D (2008) Adverse effects of pharmacotherapies for attention-deficit hyperactivity disorder: epidemiology, prevention and management. CNS Drugs 22(3):213-237

3. Graham J, Banaschewski T, Buitelaar J, Coghill D, Danckaerts M, Dittmann RW, Döpfner M, Hamilton R, Hollis C, Holtmann M, Hulpke-Wette M, Lecendreux M, Rosenthal E, Rothenberger A, Santosh P, Sergeant J, Simonoff E, Sonuga-Barke E, Wong IC, Zuddas A, Steinhausen HC, Taylor E, European Guidelines Group (2011) European guidelines on managing adverse effects of medication for ADHD. Eur Child Adolesc Psychiatry 20(1):17-37

4. Nissen SE (2006) ADHD drugs and cardiovascular risk. N Engl J Med 354(14):1445-1448

5. European Medicines Agency (2007) PRESS RELEASE: Meeting highlights from the Committee for Medicinal Products for Human Use, 16-19 July 2007. London: European Medicines Agency. http://www.emea.europa.eu/docs/en_GB/document_library/ Press_release/2009/12/WC500017068.pdf. Accessed 12 September 2012

6. European Medicines Agency (2009) European Medicines Agency makes recommendations for safer use of Ritalin and other methylphenidate-containing medicines in the EU. London: European Medicines Agency. http://www.ema.europa.eu/docs/ en_GB/document_library/Press_release/2009/11/ WC500014589.pdf (accessed 12/09/2012)

7. Neubert A, Sturkenboom MC, Murray ML, Verhamme KM, Nicolosi A, Giaquinto C, Ceci A, Wong IC (2008) Databases for pediatric medicine research in Europe-assessment and critical appraisal. Pharmacoepidemiol Drug Saf 17(12):1155-1167

8. European Medicines Agency (2005) Guideline on risk management systems for medicinal products for human use. European Medicines Agency, London

9. Gau C-S, Chen C-F, Gau SS-F (2010) The influence of using methylphenidate on the coming up of psychiatric disorders in children with ADHD. Pharmacoepidemiol Drug Saf 19(S1): S152-S153

10. McCarthy S, Cranswick N, Potts L, Taylor E, Wong IC (2009) Mortality associated with attention-deficit hyperactivity disorder (ADHD) drug treatment: a retrospective cohort study of children, adolescents and young adults using the general practice research database. Drug Saf 32(11):1089-1096

11. Cooper WO, Habel LA, Sox CM, Chan KA, Arbogast PG, Cheetham TC, Murray KT, Quinn VP, Stein CM, Callahan ST, Fireman BH, Fish FA, Kirshner HS, O’Duffy A, Connell FA, Ray WA (2011) ADHD drugs and serious cardiovascular events in children and young adults. N Engl J Med 365(20):1896-1904

12. Winterstein AG, Gerhard T, Kubilis P, Saidi A, Linden S, Crystal S, Zito J, Shuster JJ, Olfson M (2012) Cardiovascular safety of central nervous system stimulants in children and adolescents: population based cohort study. BMJ 345:e4627. doi:10.1136/ bmj.e 4627

13. Hsia Y, Neubert A, Sturkenboom MC, Murray ML, Verhamme KM, Sen F, Giaquinto C, Ceci A, Wong IC, on behalf of the TEDDY Network of Excellence (2010) Comparison of antiepileptic drug prescribing in children in three European countries. Epilepsia 51(5):789-796

14. Sen EF, Verhamme KM, Neubert A, Hsia Y, Murray M, Felisi M, Giaquinto C, 't Jong GW, Picelli G, Baraldi E, Nicolosi A, Ceci A, Wong IC, Sturkenboom MC, on behalf of the TEDDY European Network of Excellence (2011) Assessment of pediatric asthma drug use in three European countries; a TEDDY study. Eur J Pediatr 170(1):81-92

15. Neubert A, Verhamme K, Murray ML, Picelli G, Hsia HF, Sen FE, Giaquinto C, Ceci A, Sturkenboom M, Wong ICK (2010) The prescribing of analgesics and non-steroidal anti-inflammatory drugs in paediatric primary care in the UK, Italy and the Netherlands. Pharmacol Res 62(3):243-248

16. Sturkenboom MC, Verhamme KM, Nicolosi A, Murray ML, Neubert A, Caudri D, Picelli G, Sen EF, Giaquinto C, Cantarutti L, Baiardi P, Felisi MG, Ceci A, Wong IC, TEDDY European Network of Excellence. (2008) Drug use in children: cohort study in three European countries. BMJ 337:a2245. doi:10.1136/bmj. a2245

17. Anon (2010) Abstracts of the 26th International Conference on Pharmacoepidemiology \& Therapeutic Risk Management, 19-22 
August 2010, Brighton, UK. Pharmacoepidemiol Drug Saf 19(S1):S1-S347

18. Schneeweiss S, Avorn J (2005) A review of uses of health care utilization databases for epidemiologic research on therapeutics. J Clin Epidemiol 58:323-337

19. Jaddoe VW, van Duijn CM, van der Heijden AJ, Mackenbach JP, Moll HA, Steegers EA, Tiemeier H, Uitterlinden AG, Verhulst FC, Hofman A (2010) The Generation R Study: design and cohort update. Eur J Epidemiol 25(11):823-841

20. Ghassabian A, Bongers-Schokking JJ, de Rijke YB, van Mil N, Jaddoe VW, de Muinck Keizer-Schrama SM, Hooijkaas H, Hofman A, Visser W, Roman GC, Visser TJ, Verhulst FC, Tiemeier H (2012) Maternal thyroid autoimmunity during pregnancy and the risk of attention deficit/hyperactivity problems in children: the Generation R Study. Thyroid 22(2):178-186. doi: 10.1089/thy.2011.0318

21. Cai B, Xu W, Bortnichak E, Watson D (2012) An algorithm to identify medical practices common to both the General Practice Research Database and The Health Improvement Network database. Pharmacoepidemiol Drug Saf 21:770-774

22. WHO Collaborating Centre for Drug Statistics Methodology. (2012) Anatomical Therapeutic Chemical classification system: structure and principles. http://www.whocc.no/atc_ddd_index/. Accessed 15 August 2012

23. European Pharmaceutical Marketing Research Association (2012). Anatomical Classification. http://www.ephmra.org/classi fication/anatomical-classification.aspx. Accessed 15 August 2012

24. World Health Organization. International Classification of Diseases (ICD). http://www.who.int/classifications/icd/en. Accessed 24 December 2012

25. American Psychiatric Association (1994) Diagnostic and Statistical Manual of Mental Disorders, Text Revision (DSM-IV-TR), 4th edn. American Psychiatric Association, Washington, DC

26. Cantwell DP (1996) Attention deficit disorder: a review of the past 10 years. J Am Acad Child Adolesc Psychiatry 35(8): 978-987. doi:10.1097/00004583-199608000-00008

27. Rucklidge JJ, Tannock R (2002) Validity of the Brown ADD scales: an investigation in a predominantly inattentive ADHD adolescent sample with and without reading disabilities. J Atten Disord 5(3): 155-164

28. Goodman R (1997) The Strengths and Difficulties Questionnaire: a Research Note. J Child Psychol Psychiatry 38:581-586

29. Panei P, Arcieri R, Bonati M, Bugarini M, Didoni A, Germinario E (2010) Safety of psychotropic drug prescribed for attentiondeficit/hyperactivity disorder in Italy. Adverse Drug Reaction Bulletin 260:999-1002

30. Didoni A, Sequi M, Panei P, Bonati M (2011) One-year prospective follow-up of pharmacological treatment in children with attention-deficit/hyperactivity disorder. Eur J Clin Pharmacol 67:1061-1067

31. Arcieri R, Germinario EAP, Bonati M, Masi G, Zuddas A, Vella S, Chiarotti F, Panei P, the Italian Attention-Deficit/Hyperactivity Disorder Regional Reference Centers (2012) Cardiovascular Measures in Children and Adolescents with Attention-Deficit/ Hyperactivity Disorder Who Are New Users of Methylphenidate and Atomoxetine. J Child Adolesc Psychopharmacol 22:423-431

32. McCarthy S, Asherson P, Coghill D, Hollis C, Murray M, Potts L, Sayal K, de Soysa R, Taylor E, Williams T, Wong ICK (2009) Attention-deficit hyperactivity disorder: treatment discontinuation in adolescents and young adults. Br J Psychiatry 194:273277

33. McCarthy S, Wilton L, Murray ML, Hodgkins P, Asherson P, Wong IC (2012) The epidemiology of pharmacologically treated attention deficit hyperactivity disorder (ADHD) in children, adolescents and adults in UK primary care. BMC Pediatrics 12(1):78 Epub

34. Kurth BM, Kamtsiuris P, Hölling H, Schlaud M, Dölle R, Ellert $\mathrm{U}$ et al (2008) The challenge of comprehensively mapping children's health in a nation-wide health survey: design of the German KiGGS-Study. BMC Public Health 8:196

35. Huss M, Hölling H, Kurth BM, Schlack R (2008) How often are German children and adolescents diagnosed with ADHD? Prevalence based on the judgment of health care professionals: results of the German health and examination survey (KiGGS). Eur Child Adolesc Psychiatry 17(Suppl 1):52-58

36. Ehrenstein V, Antonsen S, Pedersen L (2010) Existing data sources for clinical epidemiology: Aarhus University Prescription Database. Clin Epidemiol 2:273-279

37. WHO. (2012) International Classification of Primary Care, Second edition (ICPC-2). http://www.who.int/classifications/icd/adap tations/icpc2/en/index.html. Accessed 15 August 2012

38. Sturkenboom M, Nicolosi A, Cantarutti L, Mannino S, Picelli G, Scamarcia A, Giaquinto C, NSAIDs Paediatric Research Group (2005) Incidence of mucocutaneous reactions in children treated with niflumic acid, other nonsteroidal antiinflammatory drugs, or nonopioid analgesics. Pediatrics 116:e26-e33

39. Lindemann C, Langner I, Kraut A, Banaschewski T et al (2012) Age-specific prevalence, incidence of new diagnoses and drug treatment of attention-deficit/hyperactivity disorder in Germany. J Child Adolesc Psychopharmacol 22:307-314

40. Coloma PM, Schuemie MJ, Trifirò G, Gini R, Herings R, Hippisley-Cox J, Mazzaglia G, Giaquinto C, Corrao G, Pedersen L, van der Lei J, Sturkenboom M, EU-ADR Consortium (2011) Combining electronic healthcare databases in Europe to allow for large-scale drug safety monitoring: the EU-ADR Project. Pharmacoepidemiol Drug Saf 20(1):1-11 